\title{
From Oh to Aha: Characteristics and Types of Environmental Epiphany Experiences
}

\author{
Melinda Storie' \\ Geography and Environmental Studies Department, Northeastern \\ Illinois University, Chicago, IL, United States \\ Joanne Vining \\ Department of Natural Resources and Environmental Sciences, \\ University of Illinois Urbana-Champaign, Champaign, IL, United States
}

\section{Abstract}

Despite the anecdotal evidence of experiences that shift the self-nature relationship, which we identify as Environmental Epiphanies, little is known about the characteristics and patterns of such experiences. In this study, we build on previous theoretical and conceptual frameworks of the Environmental Epiphany concept and report descriptive and typological findings based on in-depth interviews with 50 participants who had experienced Environmental Epiphanies. We present common characteristics of these experiences as well as descriptive information across five types of Environmental Epiphanies: Aesthetic, Intellectual, Realization, Awakening, and Connectedness. Based on our findings, we offer many areas for further exploration of this phenomenon as a psychological function as well as some recommendations for land managers, educators, and other environmental practitioners. Expanding our knowledge of how human-nature relationships function has implications regarding environmental decision-making, the role of emotions in self-nature relationships, and environmentally responsible behavior.

Keywords: Environmental Epiphanies; emotional experiences in nature; humannature interactions

1 Corresponding author: ms-storie@neiu.edu. 


\section{Introduction}

A very strong feeling came over me that ... and this I did not expect at all ... the only way I could describe it was that I was ... I had left my human family and entered a larger family. So, I was like no longer just the daughter of my human parents; I was the daughter of the universe. [excerpt from participant interview]

As the human response to environmental problems grows increasingly urgent, understanding how humans conceptualize and relate to "nature" is of vital importance (Vining et al., 2008). Part of this examination is the exploration and understanding of the exceptional experiences (Palmer \& Hastings, 2013) in nature. While this category of experiences is arguably part of the universal human experience (Merrick, 2008), it has received little empirical consideration. This may be a result of the ineffable quality of such experiences. However, the potential for significant environmental behavioral change motivates researchers to explore methodological frameworks that help us to understand these sometimes life-changing experiences more fully.

In this piece, we draw on the theoretical and conceptual frameworks outlined in our previous work (Vining \& Merrick, 2012) and report in more detail the findings from a study spanning several years that focused on the phenomenon of Environmental Epiphanies. Specifically, our purpose with this ongoing study is to understand the phenomenon of Environmental Epiphanies by identifying any common aspects or qualities of the experience. We also wish to explore contributing factors, place characteristics, and consequences of Environmental Epiphanies from the perspective of those who have experienced them. Our goal is to offer descriptive evidence of the common themes and patterns we found in our ongoing exploration of this multifaceted phenomenon.

\section{Defining environmental epiphanies}

We developed the concept of Environmental Epiphanies from analysis of existing data that dealt with human-nature interactions, mostly from assessments of public reactions to forest management scenarios (e.g., prescribed burns) and through open-ended questions in survey and interview data. Within these data sets (Vining \& Merrick, 2008; Merrick \& Vining, 2006), we consistently identified passages in which people described environmental experiences accompanied by intense emotions such as awe and wonder, magical experiences, and self-described life-changing moments. We also collected anecdotal evidence of our students' nature experiences through the reading of their environmental autobiographies, as well as our own magical experiences in nature. These participants and students seemed to have experienced a shift in the way in which they perceived themselves in relation to nature or natural environments and, in many cases, it changed their lives in meaningful ways. 
The human-nature interaction literature shows that these general types of experiences were referred to in different ways (e.g., peak, flow, epiphanies, sudden insights, aesthetics, awe, fascination, transformative, transcendent, and exceptional), but each shared several similar characteristics. Scholars have formally discussed (many times anecdotally) this phenomenon for over 100 years (see James, 1902) and probably much longer in terms of religious and spiritual experiences in nature (e.g., Cristancho \& Vining, 2004; Keltner \& Haidt, 2003). We coupled this general group of transformative experiences that have been discussed in terms of religious conversion, spiritual enlightenment, and quantum change (Miller \& C'de Baca, 2001), with our empirical observations regarding human-nature experiences to devise the concept of Environmental Epiphanies.

The working definition of Environmental Epiphanies follows. It is purposely general, to allow for further refinement by study participants and subsequent research.

Environmental Epiphany: An experience in which one's perception of the essential meaning of their relationship to nature shifts in a meaningful manner.

This working definition purposefully does not include the words environment or epiphany. For an in-depth discussion of our formulation of this concept, see Vining and Merrick (2012, p. 497).

\section{Review of the literature}

The general topic of positive human experiences in nature has received increasing attention in popular scientific literature. For example, National Geographic articles such as "This is your brain on nature" (Williams, 2016) and "We are wired to be outside" (Worrall, 2017), and books such as The nature fix (Williams, 2017) and Vitamin $N$ (Louv, 2016) have enjoyed recent widespread readership. This pattern reflects that researchers have continued to explore the benefits of spending time and connecting with nature in terms of improving elements of human health (Ulrich, 1984; Kaplan \& Kaplan, 1989; Kuo, 2015) and happiness (Kidner, 2007).

The empirical literature and theoretical foundations that support the exploration of similar experiences originate in a variety of disciplines (for a full review, see Vining \& Merrick, 2012, p. 497), including psychology, leisure studies, and environmental education. Keltner and Haidt (2003) outlined the contributions related to the concept of awe from disciplines such as religious studies, sociology, philosophy, and psychology. We have mainly approached the exploration of Environmental Epiphanies from a conservation psychology perspective since the concept of Environmental Epiphanies appears to emphasize "the reciprocal relationships between humans and the rest of nature" (Saunders, 2003, p. 138). Specifically, some of what we know about the theory underlying epiphany-like experiences comes 
from the work of seminal figures in psychology, such as James (1902) and Maslow (1964). In addition, scholars such as Kelly et al. (2007) have built off the work of F. W. H. Myers and his contribution to the field of psychical research. In addition, contemporary scholars have contributed work regarding similar phenomena from various psychological perspectives (e.g., Kaplan \& Talbot, 1983; Keltner \& Haidt, 2003; Miller \& C'de Baca, 2001; Williams \& Harvey, 2001, Csikszentmihalyi, 1990; Marshall, 2015).

\section{Characteristics and typologies of epiphany-like experiences}

The obvious gap in the empirical investigation of ineffable and exceptional experiences such as Environmental Epiphanies, is notable upon an interdisciplinary review of the literature. Kelly and Grosso (2007) argue that while the psychological study of mystical experiences is essential in our understanding of the human experience it is rife with empirical, disciplinary, and intellectual conundrums. Nevertheless, we have attempted to weave together insights from various aspects of studies related to "epiphany-like" experiences.

Although to our knowledge other scholars have not specifically explored the concept of Environmental Epiphanies, we found literature that outlines some of the characteristics of epiphany-like experiences. James (1902) outlines four characteristics of mystical experiences (not necessarily involving religion): ineffability, noetic quality, transiency, and passivity. Other characteristics of epiphany-like experiences include unity, transcendence, awe, positivity, and distinctiveness (mystical experience as described by Pahnke, 1963); universal unity, lack of ego, and gratitude (peak experiences as described by Maslow, 1964); and vividness, surprise, benevolence, and endurance (quantum change as described by Miller \& C'de Baca (2001).

In their extensive review of multi-disciplinary literature surrounding the aesthetic experiences in the landscape, Chenoweth and Gobster (1990) found four themes: the experiential view of the experience, the ecology (i.e., temporal and spatial aspects) of the experience, the object of the experience, and the subjective value (i.e., psychology) of the experience. Schroeder (2002) identifies psychological characteristics of special places including naturalness, remoteness, and gratitude. In terms of restorative and wilderness environments, Kaplan and Talbot (1983) offer the characteristics of being away, fascination, coherence, and compatibility, while stating the enduring aspect of wilderness experiences suggest "some basic changes in their [participants'] long-term view of the world and their relationship to it" (p. 185). Williams and Harvey (2001) add that fascination, novelty, and compatibility are dimensions of transcendent experiences in forested environments. 
In addition to characteristics of epiphany-like experiences, scholars posit several levels or types of experiences. James (1902) explores the gradations of mystical experiences and suggests that there may be levels of experiential intensity. He discusses in detail the "varieties" of religious experiences that range in levels of intensity and mentions a "pronounced step forward on the mystical ladder" when describing the most intense types of mystical experiences (James, 1902, p. 331). In work closely tied to our concept of Environmental Epiphanies, Miller and C'de Baca (2001) distinguish two levels of quantum change: insights and epiphanies. Insights reveal new perspectives, realizations, and understanding and occur within the scope of everyday experience, while epiphanies are extraordinary, mystical, and overwhelming. In their study of forested environments, Williams and Harvey (2001) further refine forms of non-transcendent (i.e., aesthetic and restorative) and transcendent (i.e., diminutive and deep flow) experiences in natural settings. Most diminutive experiences involve a part of the natural environment, while deep flow experiences involve absorbing, relaxing, and effortless experiences in mostly open and familiar natural settings.

\section{Emotional qualities of epiphany-like experiences}

The need to understand and explore the role of emotion in Environmental Epiphanies is essential given the role of emotions in decision-making practices (Isen, 2000; Vining, 1987) and as a motivational factor in environmental perceptions and actions (Vining \& Schroeder, 1989; Vining \& Tyler, 1999). As we expected, the emotionally intense aspect of epiphany-like experiences is a common theme in the literature. Both James (1902) and Maslow (1964) highlight the intense emotions that tend to be present during such experiences. James' typology of mystical experiences suggests higher and higher emotional levels of intensity, while Maslow (1964) mentions his peak experience participants reported emotions such as "wonder, awe, reverence, humility, surrender, and even worship before the greatness of the experience" (p. 65). Maslow goes on to argue that peak experiences are the result of the union of emotional intensity, experience, and the development of values, specifically "being" values, such as truth, beauty, wholeness, and aliveness.

Chenoweth and Gobster (1990) include emotion in their content analysis of aesthetic experiences in nature and observe that "emotional responses associated with aesthetic experience were frequently included in prose descriptions" (p. 6). In his exploration of sacred and special places, Schroeder (2002) highlights the emotions of awe, a sense of wonder, and magic. Kaplan and Talbot (1983) also identify the emotional experiences of awe, wonder, and spirituality in their longitudinal study of wilderness experiences. In addition to these emotions, Kaplan and Talbot found their participants tended to have improved self-esteem, a higher interest in natural processes, and a greater likelihood of self-realization and awareness. 
Ulrich et al. (1991) demonstrate the emotional difference in the way in which participants react to natural settings as opposed to urban settings. Experiencing a quantum change was also found to be profoundly emotional. Miller and C'de Baca (2001) describe these experiences as "often deeply moving," tending to release "chronic negative emotions" (p. 14), and were often incredibly positive (i.e., benevolent).

\section{Place and epiphany-like experiences}

Natural outdoor environments play an essential, although not required, role in epiphanic experiences. As we are exploring Environmental Epiphanies, we expect the setting or the object to have more significance than other experiences of epiphanies. This expectation is theoretically and empirically based in the literature we reviewed. Similarly, Williams and Harvey (2001) observe that most researchers "have observed that natural environments have a close association with transcendent experience" (p. 249). Finally, Schroeder (1991) states that "natural environments seem to be the primary setting for spiritual experiences" (p. 4).

There are many insights related to epiphany-like experiences in place attachment literature (see Bott et al., 2003; Mazumdar \& Mazumdar, 1993; Mitchell et al., 1993; Schroeder, 2002). These investigators suggest that past experience, memory, landscape attributes, symbolic representations, and other psychological factors all influence the ways in which place is negotiated by participants. Therefore, it is essential that any exploration of shifts in the self-nature relationship should address the place in which these experiences occur, in addition to exploring the psychological components of those who are affected.

The purpose of our study was to explore research participants' descriptions of Environmental Epiphany experiences. We aimed to describe patterns found across Environmental Epiphany types. In addition to contributing to understanding basic psychological processes associated with Environmental Epiphanies, we wish to aid land managers, planners, environmental educators, and those working in the conservation psychology field to more fully understand human-nature relationships.

\section{Method}

\section{Participants}

The participants for this study were 50 adults from three main geographic locations (i.e., six from a small semi-urban community in the southeastern United States (US), 12 from a midsized Midwestern US college town, and the remainder [64\%] from a large metropolitan US urban area). All participants were recruited and interviewed over a period of 10 years (i.e., 2007-2017). 
The mean age of the participants at the time of their interview was 41 with a range of 19 to 72 . Of our sample, $64 \%$ self-identified as females, $34 \%$ as males, and $2 \%$ (one participant) self-identified as intergender. The majority of our participants (92\%) reported Caucasian/European descent, 4\% identified as Asian, and 4\% as Hispanic. All participants had at least some college education. One-fifth of our participants had finished some college education, 36\% had completed undergraduate degrees, $10 \%$ had some graduate school education, and $34 \%$ had advanced (i.e., graduate) degrees. A discussion of these patterns follows in the subsequent section.

\section{Procedures}

We recruited participants by posting flyers in public locations such as libraries, coffee shops, restaurants, retail outlets, grocery stores, and schools. Some participants were also recruited through announcements in email list serves. To recruit participants, we used the operational definition of Environmental Epiphanies: An experience in which one's perception of the essential meaning of their relationship to nature shifts in a meaningful manner. Each person was screened beforehand to ensure they were aged 18 years or over and had an experience that the participant defined as changing their relationship to nature.

The first author conducted all interviews using a semi-structured protocol, partly informed by Miller and C'de Baca's (2001) study of insights and epiphanies (used with permission). We added interview items about the place where the epiphany occurred, as well as information about subsequent environmentally responsible attitudes, values, and behavior. The protocol items fell within the following categories:

- an in-depth description of the epiphany, and elements leading up to the epiphany

- basic experiential information (e.g., time, place, duration and sensations)

- the ending and after-effects of the epiphany

- a discussion of other Environmental Epiphanies experienced (if any)

- general reflections.

For a complete copy of the protocol, please contact the corresponding author.

Interviews took place in semi-private settings, most of which were conference rooms at academic or public facilities. We audio-recorded and transcribed verbatim all the interviews. After the recording ended, we asked each participant general demographic information including age, gender, education, ethnicity, and type of employment. We compensated all participants with $\$ 20.00$ or with a $\$ 20.00$ bookstore gift certificate. Interviews lasted from 30 minutes to two hours, with most lasting between 45 minutes to one hour. 
After transcribing each of the 50 interviews, we initially reviewed each conversation as a unit of analysis. We recorded the categorical variables such as time, duration, and onset using Statistical Package for the Social Sciences software. We used QSR NVivo (qualitative analysis software) to document our thematic analyses. Both authors reviewed the transcripts separately, using grounded theory to guide our content analyses. Next, we reviewed our analyses, negotiated differences, and agreed upon thematic categories and the organization of the coding scheme. We used an external coder for a portion of the transcriptions to verify that our coding categories accurately reflected the data. Throughout this process, we tried to honor the lived experience of our participants, as well as maintain as much of their original language and meaning as possible.

\section{Results}

Although several of our interview items garnered strictly qualitative data, we had many items that were more quantitative in nature (noted under descriptive results below) that we categorized. Therefore, we had a robust qualitative data set that included responses to items such as the epiphany description, as well as several categorical items such as whether the onset was sudden or gradual. We first report the descriptive (categorical) knowledge we gained in studying Environmental Epiphanies. Then, we discuss in detail the typology of epiphanies that emerged from our participants' epiphany descriptions. Within this typology, we present some analysis of observed patterns between the categorical data and the types of epiphanies to be explored in future studies of this phenomenon. Thematic analysis of participants' epiphany descriptions is beyond the scope of this paper; however, we explore this aspect of the project separately.

\section{Descriptive results}

Age: the mean age of participants at the time of their Environmental Epiphany was 31.6 years with a range of 3.67 years. The nearly 10 -year difference between the mean age at the time of the interview (41.5) and the mean age of the epiphany (31.6) suggests that these are enduring experiences. The majority (46\%) of participants reported having epiphanies in their teens and 20 s, $34 \%$ in their 30 s and 40 s, $14 \%$ after the age of 50 , and $6 \%$ before they were 10 years old.

Time of day and season: $20 \%$ of participants reported morning epiphanies, $24 \%$ during the afternoon, and $12 \%$ stated "daytime." Although over half of the reported epiphanies happened during daylight hours, six participants' epiphanies occurred in the evening or at night. Almost one-quarter of our participants reported that the epiphany experience was continuous (lasted) throughout different parts of the day, and four of our participants were unsure or could not remember what time 
of day their epiphany occurred. Almost half (48\%) of epiphanies occurred during the summer months, with the fall season being the next most frequent $(20 \%)$. Notably, $16 \%$ of participants were unsure about the season in which their epiphany occurred.

Duration: it was typical for participants to have difficulty articulating the duration of their epiphany experiences. The most common response (32\%) was that the epiphany lasted for as long as the participant was in the Environmental Epiphany place or performing the activity, while $18 \%$ of participants reported that their experiences lasted mere seconds or were fleeting. There was a wide range of responses to this question, from fleeting to four hours. As shown in Figure 1, there was no clear pattern of duration for the whole dataset. However, duration patterns emerged by epiphany type (see discussion below).

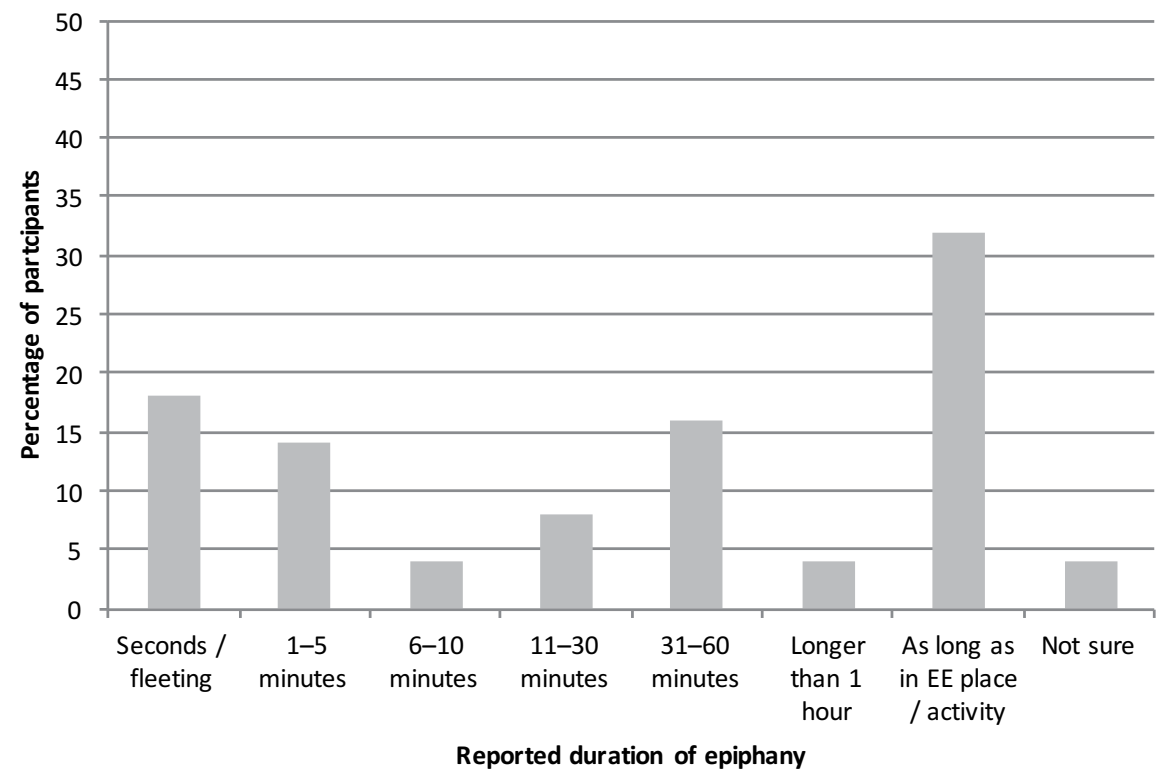

Figure 1: Participant-reported duration of Environmental Epiphany

Context: the majority (70\%) of participants reported being in an unusual location and/or engaging in an out-of-the-ordinary activity when their epiphanies occurred. The remainder were doing their regular daily routines. A similar number of participants $(72 \%)$ said that they were not attempting to have this type of experience. However, almost one-quarter reported attempting to have an experience of this type, even if they did not think of it beforehand as an Environmental Epiphany. These participants described themselves as being open to the possibility of a new and unique experience. Despite this, $74 \%$ of participants reported that the experience surprised them when it was happening. Almost two-thirds (62\%) of our participants 
reported their experience as having a sudden rather than a gradual onset. However, the participants described the ending as being mostly gradual (62\%) rather than sudden $(38 \%)$. When participants were asked if other people played a significant role or if their experiences were solitary events, over half $(56 \%)$ of epiphanies were reported to be solitary, while others reported one other person (14\%) or a group of people $(14 \%)$ who had an influential role. Some (16\%) reported that their experiences included components that were experienced both individually and as a group or with one other person.

Place: the places in which the Environmental Epiphanies occurred were as numerous as the number of participants. However, a few categories emerged from our analyses of participants' responses of their epiphany places. As expected, since we recruited all the participants from locations within the US, the majority of epiphanies took place in the US, with $58 \%$ occurring in designated natural areas (e.g., wilderness areas, national parks, national forests, and forest preserves), and $12 \%$ occurring in other US locations, mostly on private property in an outdoor location. Some (14\%) participants experienced epiphanies in international locations outside the US. Others experienced epiphanies inside their home (10\%), or outside their home in a yard (6\%). Overall, $90 \%$ of participants' epiphanies occurred outdoors. For three-quarters of our participants, the significance of the place changed after their epiphany experience.

Objects of interest: in addition to place, we assessed whether participants' experiences involved an object or focus of interest. In $68 \%$ of cases, participants included some type of object of interest that played a central role in their Environmental Epiphany. Although too numerous and varied to list, objects of interest included non-human living things (i.e., butterfly, cicada, snake, dog, bluebird, and forests), other natural phenomena (i.e., prairie, glacier, ravine, sun, volcano, mountains, and northern lights), environments with water features (i.e., ocean, waterfall, and river), built structures (i.e., the Acropolis), and media (i.e., Silent Spring, newspaper article, and documentary).

Changes and persistence of change: one of our most substantial findings was that $80 \%$ of our participants reported changes in their environmental attitudes, values, or behavior. In response to this item, participants discussed being more aware and curious about the environment after experiencing the Environmental Epiphanies that they reported. Some expressed feeling more connected to various aspects of the environment. Many discussed specific changes they made, such as becoming vegetarian or eliminating hazardous household chemicals. We also asked participants about other changes (i.e., relationships, careers, and spiritual) that occurred due to their epiphanies. Strikingly, when we asked how persistent the changes were that participants made, $90 \%$ said that the changes they made after their Environmental 
Epiphanies either completely or mostly lasted until the date of their interview. Only $10 \%$ of participants noted that the changes had somewhat lasted and none of the participants reported the changes not lasting at all.

Other Environmental Epiphanies: some participants who approached us about the study had more than one experience that met the criteria of the study. In these cases, we asked participants to describe the epiphany that was the most memorable and stood out the most. Near the end of each interview, we asked participants about any other Environmental Epiphanies that had occurred before or after the reported one and, in some cases, they gave short descriptions of their other Environmental Epiphanies. Most (70\%) noted that the reported epiphany occurred first, but once participants had experienced an epiphany, many (58\%) were more likely to experience subsequent ones.

\section{Verifying mutual understanding of the Environmental Epiphany concept:} we wanted to determine if the term "Environmental Epiphany" made sense to participants in the way in which we were using it. The majority (78\%) of our sample indicated that they agreed this phrase characterized their experience, $16 \%$ preferred calling their experience something else (i.e., a spiritual epiphany, an "aha" or "lightbulb" moment), and three people were unsure about what to call their experiences or felt there were no words to describe what they had experienced. The latter is often a characteristic of attempts to describe transcendent experiences or strong emotions and is what James (1902) described as noetic but ineffable (p. 329).

\section{Epiphany types}

We developed a typology of Environmental Epiphanies in a 2007-2008 sample of 34 participants (Merrick, 2008). Next, we performed grounded analyses on the additional data from 16 participants, in part to test the validity of the typology. While there is a risk of confirmation bias in doing this, we did not have access to an independent reviewer. As we note later in this paper, we welcome data or analyses that support, or dispute, this categorization. It is important to acknowledge that our analyses may not have produced an exhaustive typology, or even the only possible one, but they provide an idea of the roles and meanings that these experiences had from the perspective of these participants. It also establishes a basis for exploring and analyzing some of these findings in future research.

The types of Environmental Epiphanies emerged from our thematic content analysis of the first interview item in which participants described, in as much detail as they could recall, their epiphany experiences. From these descriptions, we developed a hierarchical thematic coding scheme as described in the method section above. We then coded all the epiphany descriptions and examined patterns across the themes. Through this process, the different types of epiphanies emerged due to the higher-level analysis of our qualitative themes. For a full discussion of how 
the typology was developed, please see the section "Epiphany types" in Vining and Merrick (2012). Within this analysis, we also discovered that the types of epiphanies varied in terms of the emotional and physical intensity by which participants described them. The following coding categories informed our exploration of the potential intensity of our typologies: types and frequency of positive and negative emotions, speaking about an emotional context such as an outpouring or release of emotions within which the experience occurred, physical sensations such as tingling or merging, the mention of metaphysical phenomena, and the discussion of spiritual or heightened experience. While we uncovered trends related to the intensity of these experiences, more exploration of this phenomenon is needed to determine whether these Environmental Epiphany types are qualitatively and universally different in terms of emotional intensity.

We then examined frequencies of descriptive variables within each Environmental Epiphany type. Although we conducted statistical analyses of descriptive findings between the types, there were few statistically different differences. Moreover, quantitative analyses of small occurrences are of dubious value. Thus, we opted to evaluate the descriptive data within each type in a more conceptual sense and as of interest to and heuristic of future research.

Our thematic analyses revealed five main types of epiphanies: Aesthetic, Intellectual, Realization, Awakening, and Connectedness. Many of our participants discussed themes that encompassed more than one type of epiphany; however, after prolonged study of the transcripts it became clear which type of epiphany captured each experience accurately. We report in Table 1 the frequencies of the primary types of Environmental Epiphany or those that played a significant role in participants' experiences. In some cases, we identified an additional epiphany type that served as more of a backdrop or as a less important component of participants' stories. While we list the Environmental Epiphany types in order of frequency in Table 1, we discuss them in an order that qualitatively reflects our developing understanding of this phenomenon.

Table 1. Frequency of Environmental Epiphany Type

\begin{tabular}{|l|c|c|}
\hline Environmental Epiphany Type & Primary Frequency & Secondary Frequency \\
\hline Aesthetic & 3 & 11 \\
\hline Intellectual & 4 & 3 \\
\hline Connectedness & 10 & 3 \\
\hline Awakening & 15 & 13 \\
\hline Realization & 18 & 6 \\
\hline Total & $\mathbf{5 0}$ & $\mathbf{3 6}$ \\
\hline
\end{tabular}


Aesthetic Environmental Epiphanies: only 6\% of participants experienced what we categorized Aesthetic Epiphanies (i.e., visually appealing, awe-struck moments in which participants were overwhelmed by the beauty or existence of something). While just 3 out of 50 participants reported this as their primary experience, 11 more described aspects of Aesthetic Epiphanies as underlying themes of their epiphany stories and we include their data in this description. In these cases, the beauty of a place often led to more profound epiphany experiences. Below are quotations from two Environmental Epiphany reports that we categorized as Aesthetic:

They took us to this ravine and it was just stunning. It was just so beautiful right then and there ... so that really started my concentrated love for the environment. [excerpt from participant interview]

Just to find a place like that where it was so peaceful and so expansive ... And just to be in that space that I never knew existed for like three hours. It was just really relaxing and it inspired me to go to more places around where I live and just investigate and walk around whenever I need a calming hour or two. [excerpt from participant interview]

Our findings showed that Aesthetic Epiphanies occurred throughout participants' lifespans in areas that are preserved and/or natural areas. They tended to have an object of interest and occurred during daytime hours in the warmer months. Aesthetic participants reported being in an unusual setting or performing a novel activity. Only one participant was attempting to have this type of experience and two reported being surprised. The onsets of Aesthetic Epiphanies tended towards gradual while all Aesthetic participants reported the endings to be sudden, upon leaving the Environmental Epiphany place. The three Aesthetic Epiphanies occurred while other people were present. The duration of all Aesthetic Epiphanies was more than 10 minutes. Further, the significance of the place changed for all these participants. All Aesthetic participants reported changes in environmental attitudes, values, or behavior. There were no discernable trends in the experience of previous or subsequent Environmental Epiphanies. Some reported having epiphanies before, and a couple communicated experiences occurring after their reported Environmental Epiphany.

Our findings regarding the Aesthetic category must be interpreted cautiously due to the frequency count. It is possible that potential Aesthetic Epiphany participants might not have responded to our recruitment protocol that emphasizes a significant shift in one's relationship to nature. We report these findings because we find them interesting in relation to the epiphany phenomenon, and because we see value in their use to inform future research.

Intellectual Environmental Epiphanies: seven participants described experiences in which they were exposed to new information that contributed to the shift in their nature-self relationship, in these cases through the reading of text or watching 
a documentary. This was the primary type of epiphany present in four of our epiphany stories. Intellectual insights played a secondary role in three other epiphany stories. These experiences were the only ones in our dataset that were not place-based, but they tended to result in profound and significant changes among the participants who experienced them. In the following example, a participant discusses reading a newspaper article about how chickens are raised and processed for consumer consumption. In the excerpt below, she describes her next trip to the grocery store:

So, the next Sunday I went to do my grocery shopping and I walked around the grocery store and I got some chicken breast and I put it in my basket. And at first, I didn't even get what was going on there. And I bought some other things and I'm looking at the chicken. And I thought, okay, I can't do this. And I put the chicken back in the freezer thing. And it wasn't like when I first picked up the chicken I had any idea that something was different here, but I just remember looking at the chicken and thinking about it. And I've never had meat since then. When I went to buy it, it was just like, okay, I can't do this. [excerpt from participant interview]

Examining the quantitative data with this Environmental Epiphany type contributed to ideas for future research. In our sample, Intellectual Epiphanies occurred throughout the lifespan in mostly home or other routine environments. The object of interest was not a natural or outdoor object, but the text that the participants read. Most participants could not recall what time of day or year it was, which makes sense given that these experiences were not place-based. Following from this, the epiphany place did not change in significance. For three out of four participants, the Environmental Epiphany came as a surprise because they were generally participating in daily routines during which they were not attempting to have an epiphany experience. All Intellectual participants reported a sudden onset and three out of four reported a gradual ending. Intellectual Epiphanies were exclusively solitary experiences ranging from fleeting to 40 minutes in duration. All Intellectual participants reported a significant and persistent change in environmental attitudes, values, or behavior. Only one participant reported experiencing a subsequent Environmental Epiphany.

Again, we must emphasize that this category of Environmental Epiphanies remained relatively small in terms of frequency count. However, we wish to maintain the qualitatively distinct characteristics of it as described above to leave open the potential to explore similar experiences in the future.

Realization Environmental Epiphanies: Realization Epiphanies were the most frequently occurring type of epiphany in our dataset, with 18 out of our 50 participants describing this as their primary type of epiphany and 6 out of 50 describing it as a secondary type of epiphany. Participants described these experiences as moments in which they realized something, similar to an "aha" or a "lightbulb" moment. This experience was described as an intense feeling of realizing something 
the participant may have previously known to be true, a new awareness, a shift in awareness of options, a change in perspective, and overcoming challenges in nature. Two participants described their Realization Epiphanies as follows:

And a couple of days before they [cicadas] started ... before we really started to see them everywhere, we had dandelions in the lawn and they came and sprayed. And this was what was so disturbing to me because we started to notice a few days after that that the ones [cicadas] that were emerging were deformed. And it made me realize that there must have been something horrible in this lawn spray that this is what it was doing to the cicadas. [excerpt from participant interview]

I feel like it's stayed with me. In a way, I feel like it was sort of like it was there to begin with and it this just sort of grounded it. It's like the difference between, like you can read about something and kind of hear stories that people have and then when you have an experience, then it's just a different kind of realization. [excerpt from participant interview]

Realization Epiphanies occurred at every age category except ages 61-70, and in every place category. About $60 \%$ of participants reported an object of interest that accompanied Realization Epiphanies. Although Realization Epiphanies occurred all times of the day and evening, more so than any other type of epiphany, participants reported that the epiphanic feeling lasted for as long as they were engaging in the Environmental Epiphany activity or place. Realization Epiphanies occurred during all times of the year, with most (72\%) occurring during the summer months.

Over $80 \%$ of Realization participants were performing an unusual activity or in a novel place with nearly all (77\%) not attempting to have an epiphany experience. Consequently, Realization Epiphanies surprised 55\% of participants. Half of Realization participants reported a sudden onset and half reported a gradual onset. Participants reported Realization endings as almost evenly split between sudden endings (44\%) and more gradual endings (55\%). Two-thirds of the Realization participants reported that at least one other person was present and part of the experience. The majority $(72 \%)$ of Realization participants reported a change in their environmental attitudes, values, or behavior due to their experiences. The participants also thought of the Environmental Epiphany place as more significant than before the Environmental Epiphany occurred. Within this category of participants, other Environmental Epiphanies were more present, with 28\% having had one before and $61 \%$ since the one they reported in this study.

Awakening Environmental Epiphanies: the second most frequently reported primary Environmental Epiphany was Awakening Epiphanies. We viewed this type as qualitatively different from Realization Epiphanies in that participants described a new clarity or an eye-opening experience. Some Awakening participants described being restored or healed by nature. They described these 
experiences as an awareness of the way things should be, a shift in consciousness, or a new vividness. Participants described Awakening Epiphanies as life-changing, life-affirming, transformative turning points:

And I was just so overcome, you know, I was crying. And I just thought, you know, this is how it should be every day. And that our air and our mountains and our views and everything just should be there for us always. And that struck my heart so hard that I ... this wasn't a radical change in my plans, but it made me decide with a very profound commitment to pursue a career in environment science. [excerpt from participant interview]

And then I just ... as he was talking, I just kind of looked up into the trees and the sun was ... had just gone behind the very top of the canopy. So I could see it kind of coming through ... the rays coming through. And the breeze was blowing and I still remember this vividly ... this image in particular. And at that moment, it just happened very quickly. I just felt all anxiety, all worry, any tension just disappear. And I ... I never have ever felt that before. And it was just ... it was an incredible feeling. [excerpt from participant interview]

And at some point, I just got incredibly choked up with emotion. And it just hit me. It was like a burst of awareness of ... this is it. You know, like this is the meaning that I've been looking for throughout my life. Like this is the feeling that I want to have. And I became really emotional and just started ... I was happy, but then I started feeling like I was going to start crying. And then I just let myself cry. So, I was like basically riding my bike and sobbing [chuckles] and just thinking about how beautiful it was and how powerful it was. [excerpt from participant interview]

Awakening participants (including primary and secondary categories) outnumbered all the other participant types with 15 participants reporting Awakening as their primary Environmental Epiphany type and 13 having secondary Awakening elements in their Environmental Epiphany descriptions. Awakening Epiphanies occurred mostly before participants were 40 years of age. None of the Awakening Epiphanies happened in the home environment and in most instances (60\%) participants were focusing on an object of interest at the time. Awakening Epiphanies occurred evenly throughout times of day and year, excluding the winter months. Like Realizations, Awakenings primarily occurred when participants (73\%) were in novel places or engaged in non-routine activities. While $20 \%$ of participants in this category were attempting to have an Environmental Epiphany, all were surprised by their experiences.

Two-thirds (66\%) of Awakening participants reported sudden rather than gradual onsets, and $73 \%$ of participants reported gradual endings. Only one-third of participants reported other people having a role in their Environmental Epiphany. Awakening experiences were fleeting in duration, although five lasted for as long as the participants were in the Environmental Epiphany place or performing the activity. All but one Awakening participant reported that the significance of the 
Environmental Epiphany place changed and most participants (73\%) reported changes in environmental attitudes, values, or behavior. Of the 15 participants, eight reported experiencing previous Environmental Epiphanies and six experienced subsequent Environmental Epiphanies.

Connectedness Environmental Epiphanies: Connectedness participants reported moments of strong connectedness, feeling a part of a larger, universal connectedness, or experiencing the interconnectedness of all. These participants (10 primary and three secondary) described a change in perception related to their feelings of connectedness with a higher power, nature, and the universe. We found these experiences exhibited high levels of positive emotions and they were often described as life-changing experiences. They sometimes had physiological effects such as tingling, which was distinct from the other Environmental Epiphany types:

Just felt very free and very ... once again, my experience was a union with everything that is, not just the water, not just the surroundings, but everything that is. [excerpt from participant interview]

And as I was leaving and going back to the house, a very strong feeling came over me that ... and this I did not expect at all ... the only way I could describe it was that I was ... I had left my human family and entered a larger family. So I was like no longer just the daughter of my human parents; I was the daughter of the universe. [excerpt from participant interview]

I felt surrounded and I thought god is in nature and that on many levels, all my senses were very acute. It was palpable. I felt like I could reach out and touch god. I felt like I was enveloped or surrounded by god. And that's the first time I've ever felt that way. And it was such a profound feeling to me that it kind of altered my view of religion. It was kind of strange in that I had never felt anything like that before. [excerpt from participant interview]

Connectedness experiences occurred mostly in participants aged between 20 and 50 years old and in all the place categories. The majority $(80 \%)$ of participants included an object of interest that precipitated the epiphany. All but one participant, who could not remember the time of their Environmental Epiphany, reported Connectedness Epiphanies occurring during daytime hours. Participants also reported that Connectedness Epiphanies occurred during all times of year except spring months. Interestingly, half of Connectedness Epiphanies occurred during routine situations, while the other half occurred when participants were engaged in unusual activities or visiting novel places. More so than any other type of epiphany, Connectedness participants (40\%) were attempting to have an Environmental Epiphany. Despite this, $70 \%$ reported being surprised by the experience.

For 7 out of 10 participants, their Connectedness Epiphanies were sudden with a gradual ending. The majority (80\%) of Connectedness Epiphanies were solitary and most were quite brief. When we asked about the duration of these experiences, 
half of these participants reported having only fleeting or seconds-long epiphanies. Although the Connectedness Epiphanies were brief and did not last for as long as the participant was in the Environmental Epiphany place, $80 \%$ of Connectedness participants reported that the place grew more significant with time. Nearly all (90\%) of participants reported changes in their environmental attitudes, values, or behavior. Most of the participants had not experienced previous Environmental Epiphanies; however, experiencing this type of epiphany led to subsequent Environmental Epiphanies for $90 \%$ of the participants.

\section{Discussion}

We now have some basic information regarding the experience of Environmental Epiphanies. We know that these experiences can happen at any time of life, even as early as toddlerhood, and that they are often very memorable experiences that persist for years. Although our participants reported Environmental Epiphanies occurring at almost all times of day and seasons of the year, most happened during daylight hours and in seasons that support higher levels of outdoor activities. It is possible for an Environmental Epiphany to last anywhere from a fleeting moment to several hours, and this is largely tied to the amount of time spent in the Environmental Epiphany setting. The novelty of the Environmental Epiphany place and activity were significant to our respondents, as was the element of surprise. Most Environmental Epiphanies had a sudden onset and gradual ending rather than the opposite. Environmental Epiphanies can happen with others present and involved or be an entirely solitary experience. Most were place-based, occurring in protected or natural areas, and attachment to these places increased because of the experience. Environmental Epiphanies were stimulated by various objects of interest. The experience of Environmental Epiphanies resulted in persistent environmental and other significant life changes. We also know that experiencing an Environmental Epiphany was associated with the experience of subsequent Environmental Epiphanies. While only 30\% of our participants reported Environmental Epiphanies before the one that was most memorable, 58\% reported having subsequent Environmental Epiphanies. Finally, for the most part, participants approved of our use of the term "Environmental Epiphany" to represent what they experienced.

Our grounded analyses revealed five distinct types of Environmental Epiphanies. Aesthetic Epiphanies involve the recognition of beauty and the existential and aesthetic value of nature. Intellectual Epiphanies are less place-based and are more cerebral insights about human-nature interactions. Realizations are more common and involve a new awareness, awareness of a different option, a change in perspective, or overcoming a challenge in nature. Awakening Epiphanies are defined by clarity, vividness, a shift of consciousness, and insights about the ways human-nature 
relationships should be. Finally, Connectedness Epiphanies are characterized by a sense of oneness, unification, or a connection with a larger whole. We encourage future research to explore, challenge, and build upon this proposed typology.

Our proposed typology of Environmental Epiphanies is similar to other conceptions of epiphany-like experiences. For example, James (1902) wrote about six gradations of mystical experiences including a simple realization, which resembles our Realization category. Miller and C'de Baca (2001) also found a realization type in their studies of insights and epiphanies. Maslow (1964) described experiences of becoming one with the universe that resemble our Connectedness Epiphanies. Williams and Harvey (2001) found themes of unification with a higher entity in their study of transcendent experiences that is also analogous to our Connectedness category. Our results mirror Chenoweth and Gobster's (1990) aesthetic component of the ecology of the experience. Their findings are also related to our analyses of the onset, duration, and significance of the epiphany place. Finally, Kals et al. (1999) and others (e.g., Schultz et al., 2004) have included feelings of oneness scales (Connectedness) to study the relationship of this construct to other variables.

We used a slightly altered version of Miller and C'de Baca's (2001) interview protocol, as they also examined insights and epiphanies. We were able to corroborate four of their characteristics of personal transformation. Our Environmental Epiphany participants reported memorable and vivid accounts of their strongly emotional experiences. Many were not attempting to have an Environmental Epiphany and were surprised by them. Their Environmental Epiphanies were mostly benevolent experiences characterized by positive emotions. These experiences and their consequences were also very enduring. Our results also revealed themes like those described as restorative benefits of nature (Kaplan, 1995) such as being away and fascination.

One of the most striking findings is that the Environmental Epiphany phenomenon appears to have common elements across participants, as well as major significance within the lives of the participants. It was not difficult to recruit participants for this study and we often had more volunteers than resources to collect their data. Many of our participants reported not having communicated their experiences to anyone until they participated in this study, which led to expressions of strong and vivid emotions during the interviews. This demonstrated to us that although these experiences are very special and significant they are not a part of our common vernacular. Perhaps if experiences such as Environmental Epiphanies were more a part of collective understanding, people would better reflect on and more readily comprehend the insights they gained through their experiences. Our study of this phenomenon has cemented our hunch that Environmental Epiphanies are an important phenomenon to study that has exciting implications. Although our participants' accounts of their experiences overlap with elements of previous epiphany-like studies, we are more certain now than ever that epiphanies associated with nature are worthy phenomena to study on their own. 
We found it striking how similar our participants' epiphany stories were to each other. With a dataset this large, our thematic and typological account of Environmental Epiphanies uncovered more similarities than differences. Regardless of typology category, most participants described being in novel places or performing new activities, traveling or journeying, experiencing positive emotions, recreational and physical activities, and connection to other people.

We believe that the places where our participants' Environmental Epiphanies occurred hold great significance in this study and in existing literature on placebased emotion. This is another area that we hope to study further to determine if there are aspects of the place that elicit these types of experiences. In particular, novel places or activities played a significant role in most of our participants descriptions of Environmental Epiphanies. However, there was also a type of Environmental Epiphany that was not place-based (Intellectual), defined by a cognitive change but still resulting in a shift of the perception of the self-nature relationship. If place plays a significant role, these types of experiences have land management implications like those in other studies of special places (e.g., Schroeder, 2002).

Objects of interest also played crucial roles in our participants' experiences of Environmental Epiphanies. However, an object of interest was not a required element of the Environmental Epiphany experience. The common characteristics of these objects of interest deserve empirical attention, as well as the role they play in the different Environmental Epiphanies.

\title{
Limitations, future directions, and conclusions
}

\begin{abstract}
Although we benefited greatly from the thick descriptions (Geertz, 1973) of our participants, our ability to determine statistical significance for our comparisons of quantitative responses between typology categories was limited. This was partly because the number of participants classified into each Environmental Epiphany type was small and because we made an explicit trade-off for qualitative exploration with a lower, but still important, emphasis on quantitative data. A stronger focus on the more descriptive aspects of Environmental Epiphanies would be helpful in characterizing the phenomenon in a more quantitative way. Similarly, the demographics of our convenience sample are more homogenous than the general population. This homogeneity prevented testing of demographic differences among the typologies. In this study, we relied on interviews, self-reports, and selfselection, each of which require decisions regarding methodological advantages and disadvantages. These are all important considerations in designing research on a phenomenon that is not necessarily experienced by a wider population.
\end{abstract}


We used the convenience sampling method to explore this phenomenon in as many participants as resources would allow. We attempted to recruit from multiple sites and include a diverse population within the confines of our time, locations, and resources. In addition, the number of participants does not reflect a point of saturation in all categories of the results (e.g., epiphany types), as might be expected in a qualitative exploration. We plan for the study of Environmental Epiphanies to be an ongoing one that can build on the exploratory knowledge we gained from this study.

These limitations may be addressed in future research as we and others continue explorations of the phenomenon of Environmental Epiphanies using various methodological tools. One of the most pronounced questions that has emerged thus far in our work is the number of people who have experienced an Environmental Epiphany. It is important to ask whether this type of experience is a factor of privilege or access to places that seem to elicit Environmental Epiphanies. Exploring these types of experiences in more diverse populations seems essential in our understanding of them.

Through our grounded analyses, we have proposed a typology of Environmental Epiphanies. We see this typology as a model to build upon, but other investigators may find other kinds of typologies, or identify nuances related to the experience of these epiphanies within our typology.

Research such as this not only helps to build the foundation for basic research that will enable a better understanding of the psychological nature of Environmental Epiphanies, it can also guide environmental managers and officials. One key factor could be the positive change in conservation attitudes and behavior that were mentioned by many of our participants_-something that requires additional research. Moreover, Vining (1992) has demonstrated that land managers and officials have strong emotions regarding the environment. Anecdotal evidence gathered during conversations with such individuals supports the idea that Environmental Epiphanies are likely experienced by these individuals and likely guide their management philosophies and actions, as well as being important factors in their career choices.

The following is a list of general suggestions to public land managers and environmental educators and interpreters based on what we know about Environmental Epiphanies:

- provide opportunities for Environmental Epiphanies by ensuring that the public continues to have access to natural areas with room for solitary contemplation

- cater to a large variety of visitors

- create more activities that promote initial exposure to natural areas

- offer group and guided activities outside the everyday 
- incorporate place attachment into land management strategies

- help to preserve natural areas as special places with input from the public

- incorporate the role of emotions in public policy and interactions with the public (i.e., volunteer management and decision-making)

- provide opportunities such as storytelling events for the public to share epiphanylike experiences to provide a supportive network that encourages the endurance of any environmental attitude or behavioral change.

We have discussed the main descriptive elements of a unique type of humannature experience, Environmental Epiphanies. Using a grounded theory approach, we identified five distinct types of Environmental Epiphanies and characterized the nature of the descriptive data for each type of epiphany. Based on our work, we believe that Environmental Epiphanies may be important psychological phenomena and that they also have environmental planning and management implications. It is our hope that our work will provide a foundation to explore these meaningful life experiences in more detail.

\section{Acknowledgments}

We are grateful for funding from the USDA Forest Service Northern Research Station and Northeastern Illinois University. We would like to thank our participants for sharing these personally meaningful stories with us. We would especially like to acknowledge our reviewers for their insightful comments and suggestions.

\section{References}

Bott, S., Cantrill, J. G., \& Myers, O. E., Jr. (2003). Place and the promise of conservation psychology. Human Ecology Review, 10, 100-112.

Chenoweth, R. E., \& Gobster, P. H. (1990). The nature and ecology of aesthetic experiences in the landscape. Landscape Journal, 9, 1-8. doi.org/10.3368/lj.9.1.1

Cristancho, S., \& Vining, J. (2004). Reciprocity as principled argument: The ethics of human-nature interactions for the Letuama. Human Ecology Review, 11(2), 36-50.

Csikszentmihalyi, M. (1990). Flow: The psychology of optimal experience. New York, NY: HarperCollins.

Geertz, C. (1973). The interpretation of cultures: Selected essays. New York, NY: Basic Books.

Isen, A. M. (2000). Positive affect and decision making. In M. Lewis \& J. M. HavilandJones (Eds.), Handbook of emotions (2nd ed., pp. 417-435). New York, NY: Guilford Press. 
James, W. (1902). The varieties of religious experience. Cambridge, MA: Harvard University Press.

Kals, E., Schumacher, D., \& Montada, L. (1999). Emotional affinity toward nature as a motivational basis to protect nature. Environment and Behavior, 31, 178-202. doi.org/10.1177/00139169921972056

Kaplan, R., \& Kaplan, S. (1989). The experience of nature: A psychological perspective. Cambridge University Press Archive.

Kaplan, S. (1995). The restorative benefits of nature: Toward an integrative framework. Journal of Environmental Psychology, 15(3), 169-182. doi.org/10.1016/0272-4944(95)90001-2

Kaplan, S., \& Talbot, J. F. (1983). Psychological benefits of a wilderness experience. In I. Altman \& J. F. Wohlwill (Eds.), Behavior and the natural environment (pp. 163203). New York, NY: Plenum. doi.org/10.1007/978-1-4613-3539-9_6

Kelly, E., \& Grosso, M. (2007). Mystical experience. In E. F. Kelly, E. W. Kelly, A. Crabtree, A. Gauld, M. Grosso, \& B. Greyson, Irreducible mind: Toward a psychology for the 21st Century (pp. 495-575). Lanham, MD: Rowman \& Littlefield.

Kelly, E. F., Kelly, E. W., Crabtree, A., Gauld, A., Grosso, M., \& Greyson, B. (2007). Irreducible mind: Toward a psychology for the 21st Century. Lanham, MD: Rowman \& Littlefield.

Keltner, D., \& Haidt, J. (2003). Approaching awe, a moral, spiritual, and aesthetic emotion. Cognition and Emotion, 17(2), 297-314. doi.org/10.1080/02699930302297

Kidner, D. W. (2007). Depression and the natural world: Towards a critical ecology of psychological distress. International Journal of Critical Psychology, 19, 123-146.

Kuo, M. (2015). How might contact with nature promote human health? Promising mechanisms and a possible central pathway. Frontiers in Psychology, 6, 1-8. doi.org/ 10.3389/fpsyg.2015.01093

Louv, R. (2016). Vitamin N: The essential guide to a nature-rich life. New York: Workman Publishing.

Marshall, P. (2015). Mystical experiences as windows on reality. In E. F. Kelly, A. Crabtree, \& P. Marshall (Eds.), Beyond physicalism (pp. 39-76). Lanham, MD: Rowman \& Littlefield.

Maslow, A. H. (1964). Religions, values, and peak experiences. Columbus, OH: Ohio State University Press.

Mazumdar, S., \& Mazumdar, S. (1993). Sacred space and place attachment. Journal of Environmental Psychology, 13, 231-242. doi.org/10.1016/S0272-4944(05)80175-6

Merrick, M. S. (2008). Environmental epiphanies: Exploring the shifts in human nature interactions. (Unpublished doctoral dissertation). University of Illinois at UrbanaChampaign, Urbana, IL. 
Merrick, M. S., \& Vining, J. (2006). Characteristics people consider when evaluating forest landscape attractiveness: Fuel management implications. In S.M. McCaffrey (Ed.), The public and wildland fire management: Social science findings for managers (pp. 63-75). Newtown Square, PA: US Department of Agriculture, Forest Service, Northern Research Station.

Miller, W. R., \& C'de Baca, J. (2001). Quantum change: When epiphanies and sudden insights transform ordinary lives. New York: Guilford Press.

Mitchell, M. Y., Force, J. E., Carroll, M. S., \& McLaughlin, W. J. (1993). Forest places of the heart: Incorporating special spaces into public management. Journal of Forestry, 91(4), 32-37.

Pahnke, W. (1963). Drugs and mysticism: An analysis of the relationship between psychedelic drugs and the mystical consciousness (Unpublished doctoral dissertation). Harvard University, Cambridge, MA.

Palmer, G., \& Hastings, A. (2013). Exploring the nature of exceptional human experiences: Recognizing, understanding, and appreciating EHEs. In H. L. Friedman $\&$ G. Hartelius (Eds.), The Wiley-Blackwell handbook of transpersonal psychology, 331-351. doi.org/10.1002/9781118591277.ch18

Saunders, C. D. (2003). The emerging field of conservation psychology. Human Ecology Review, 10, 137-149.

Schroeder, H. W. (1991, April). The spiritual aspect of nature: A perspective from depth psychology. Paper presented at the Northeastern Recreation Research Conference, Saratoga Springs, New York.

Schroeder, H. (2002). Experiencing nature in special places: Surveys in the north-central region. Journal of Forestry, 100(5), 8-14.

Schultz, P. W., Shriver, C., Tabanico, J. J., \& Khazian, A. (2004). Implicit connections with nature. Journal of Environmental Psychology, 24, 31-42. doi.org/10.1016/S02724944(03)00022-7

Ulrich, R. (1984). View through a window may influence recovery. Science, 224(4647), 224-225. doi.org/10.1126/science.6143402

Ulrich, R., Simons, R., D. Losito, B., Fiorito, E., Miles, M., \& Zelson, M. (1991). Stress recovery during exposure to natural and urban environments. Journal of Environmental Psychology, 11, 201-230. doi.org/10.1016/S0272-4944(05)80184-7

Vining, J. (1987). Environmental decisions: The interaction of emotions, information, and decision context. Journal of Environmental Psychology, 7, 13-30. doi.org/10.1016/ S0272-4944(87)80042-7

Vining, J. (1992). Environmental emotions and decisions: A comparison of the responses and expectations of forest managers, an environmental group, and the public. Environment and Behavior, 24, 3-34. doi.org/10.1177/0013916592241001 
Vining, J., \& Merrick, M. S. (2008). The influence of proximity to a national forest on emotions and fire-management decisions. Environmental Management, 41, 155-167. doi.org/10.1007/s00267-007-9041-y

Vining, J., \& Merrick, M. S. (2012). Environmental epiphanies: Theoretical foundations and practical applications. In S. D. Clayton (Ed.), The Oxford handbook of environmental and conservation psychology (pp. 485-508). New York: NY: Oxford University Press. doi.org/10.1093/oxfordhb/9780199733026.013.0026

Vining, J., Merrick, M. S., \& Price, E. A. (2008). The distinction between humans and nature: Human perceptions of connectedness to nature and elements of the natural and unnatural. Human Ecology Review, 15, 1-11.

Vining, J., \& Schroeder, H. W. (1989). Emotions in environmental decision-making: Rational planning versus the passionate public. In M. L. Miller, R. Gale, \& P. Brown (Eds.), Social science in natural resource management systems. Boulder, CO: Westview Press.

Vining, J., \& Tyler, E. (1999). Values, emotions, and desired outcomes reflected in public responses to forest management plans. Human Ecology Review, 6(1), 21-34.

Williams, F. (2016, January). This is your brain on nature. National Geographic, 48-67.

Williams, F. (2017). The nature fix: Why nature makes us happier, healthier, and more creative. New York, NY: W. W. Norton Company.

Williams, K., \& Harvey, D. (2001). Transcendent experience in forest environments. Journal of Environmental Psychology, 21, 249-260. doi.org/10.1006/jevp.2001.0204

Worrall, S. (2017, February). We are wired to be outside. National Geographic. Retrieved from: news.nationalgeographic.com/2017/02/nature-fix-brain-happy-florence-williams/ 
This text is taken from Human Ecology Review, Volume 24, Number 1, 2018, published 2018 by ANU Press, The Australian National University, Canberra, Australia.

doi.org/10.22459/HER.24.01.2018.08 